\title{
Uncertainties on mean areal precipitation: assessment and impact on streamflow simulations
}

\author{
L. Moulin ${ }^{1,2}$, E. Gaume ${ }^{1,3}$, and C. Obled ${ }^{4}$ \\ ${ }^{1}$ Université Paris-Est, Cereve, UMR - MA102 Agroparistech, 77455 Marne la Vallee 2, France \\ ${ }^{2}$ UPMC Univ Paris 06, UMR 7619 Sisyphe, 75005 Paris, France \\ ${ }^{3}$ Lab Cent Ponts \& Chaussees, 44341 Bouguenais, France \\ ${ }^{4}$ Grenoble INP, Lab. LTHE, BP 53, 38041 Grenoble 9, France
}

Received: 3 July 2008 - Published in Hydrol. Earth Syst. Sci. Discuss.: 1 August 2008

Revised: 1 December 2008 - Accepted: 28 December 2008 - Published: 4 February 2009

\begin{abstract}
This paper investigates the influence of mean areal rainfall estimation errors on a specific case study: the use of lumped conceptual rainfall-runoff models to simulate the flood hydrographs of three small to medium-sized catchments of the upper Loire river. This area $\left(3200 \mathrm{~km}^{2}\right)$ is densely covered by an operational network of stream and rain gauges. It is frequently exposed to flash floods and the improvement of flood forecasting models is then a crucial concern. Particular attention has been drawn to the development of an error model for rainfall estimation consistent with data in order to produce realistic streamflow simulation uncertainty ranges. The proposed error model combines geostatistical tools based on kriging and an autoregressive model to account for temporal dependence of errors. It has been calibrated and partly validated for hourly mean areal precipitation rates. Simulated error scenarios were propagated into two calibrated rainfall-runoff models using Monte Carlo simulations. Three catchments with areas ranging from 60 to $3200 \mathrm{~km}^{2}$ were tested to reveal any possible links between the sensitivity of the model outputs to rainfall estimation errors and the size of the catchment. The results show that a large part of the rainfall-runoff (RR) modelling errors can be explained by the uncertainties on rainfall estimates, especially in the case of smaller catchments. These errors are a major factor limiting accuracy and sharpness of rainfallrunoff simulations, and thus their operational use for flood forecasting.
\end{abstract}

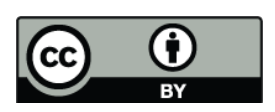

Correspondence to: L. Moulin

(laetitia.moulin@gmail.com)

\section{Introduction}

Despite decades of developments and testing, rainfall-runoff (RR) models are still seldom used by operational flood forecasting services. This is particularly true in flash-flood prone areas where accurate RR simulations would yet be necessary to compute short lead-time forecasts. The lack of accuracy and robustness of RR models, while not striking (see Chahinian et al. (2006) for a review of models and performances), remains critical for some applications.

This raises the question of the sources of uncertainties affecting RR simulations: what are the major factors limiting the accuracy of RR simulations? Which ones need particular attention? Is there any possibility of improving simulations? A better insight into these questions is necessary to give some guidance to future research work on RR modelling. It will also improve the assessment of the capabilities and limits of existing models. Among the various sources of uncertainty affecting RR modelling (Melching, 1995), uncertainties of computed precipitation play a particular role (Sun et al., 2000; Bardossy and Das, 2008). Rainfall rates are the main input data of RR models and, in that sense, are one of the first factors controlling the accuracy of RR simulations. The general issue of the impact of rainfall inputs on RR simulation accuracy encompasses at least two main questions:

- the level of spatial and temporal discretisation needed to represent accurately the RR processes dynamics in hydrological models, generally assessed through sensitivity analyses (Michaud and Sorooshian, 1994; Vischel and Lebel, 2007; Segond et al., 2007),

Published by Copernicus Publications on behalf of the European Geosciences Union. 
- the assessment of the intrinsic quality of the mean areal precipitation (MAP) estimated over the whole catchment under consideration in the case of lumped RR models (or over each of the sub-units defined in distributed models); and then the assessment of its consequences on RR simulations.

The first question is linked to the debate about the relative merits of distributed versus lumped hydrological models. It is not the focus of this paper but will be mentioned in the conclusion section. The answer to the second question depends on the rainfall measuring techniques. Weather radar coverage has dramatically increased over the last few decades giving access to measurements at high spatial and temporal resolutions. Radar signal treatment methods have significantly been improved (Krajewski and Smith, 2002; Gourley and Vieux, 2006; Chapon et al., 2008). However, quantitative precipitation estimates still present difficulties. Research works are ongoing to evaluate radar rainfall estimation errors and the suitability of radar data for hydrological applications (Carpenter et al., 2001; Borga, 2002; Carpenter and Georgakakos, 2004; Borga et al., 2006; Cole and Moore, 2008). But in many cases, quantitative precipitation estimates used as input to hydrological models and especially flood forecasting models still rely on raingauge measurements. It is especially the case for the upper Loire catchment, the selected study area, where due to implementation problems, no quantitative precipitation estimates can be retrieved from the radar data. The question of the assessment of the uncertainties of MAP estimated through raingauge measurements remains therefore active. Moreover, an accurate assessment of both the associated uncertainties and their impact on RR simulations would define a reference state to evaluate the gains due to improvements of rainfall measurement techniques.

When raingauge data are used to estimate Mean Areal Precipitation (MAP), the major source of input uncertainty comes from the lack of representativeness of a discrete set of gauges of a network (Dulal et al., 2006; Refsgaard et al., 2006; Rode and Suhr, 2007; Villarini et al., 2008) and from the necessity to interpolate the rain rates between these points. Beyond the acknowledgment of the importance of MAP estimation uncertainties, a detailed assessment of their possible impact on the RR simulations has two main practical objectives:

- To evaluate the possible gains that could be obtained through an improvement of the rainfall measuring techniques, especially the radar system.

- To determine the rainfall estimation uncertainty level to be able to turn from the standard deterministic hydrological forecasting approach (disappointing since it frequently fails to deliver correct forecasts), to a stochastic approach taking into account all the possible streamflow variation given the uncertainties about actual rainfall amounts.
Most of the previous studies on MAP uncertainty propagation in RR models were either empirical or purely theoretical sensitivity analyses. Empirical analyses are generally based on the comparison of various interpolation approaches (Creutin and Obled, 1982; Lebel et al., 1987; Johansson, 2000) or based on under-sampling of relatively dense raingauge networks (Anctil et al., 2006; Balme et al., 2006; Bardossy and Das, 2008). Theoretical analyses are based on an a priori chosen error model to corrupt the computed MAPs (Xu and Vandewiele, 1994; Paturel et al., 1995; Nandakumar and Mein, 1997; Carpenter and Georgakakos, 2004; Oudin et al., 2006). It is typical in those cases that no validation of the error model is done to ensure consistency with the available data.

The main contributions of the present work are the effort made to build, calibrate and validate a realistic error model on MAP estimates and the detailed analysis of the link between MAP estimation uncertainties, catchment area and streamflow simulation uncertainties. The following presentation of developments around the definition and validation of a rainfall estimation error model may appear sophisticated. This sophistication is however not a scientific gadget: the realism of the error model is a necessary condition to draw any valuable conclusion from the propagation of these errors into RR models. Inspired by the methodology used by Storm et al. (1989) and Datin (1998), the proposed approach relies on geostatistical tools. The selected method for evaluating MAP errors and their impact on the simulated streamflows is composed of three steps :

1. Calibration and validation of an hourly rainfall interpolation error model.

2. Calibration and validation of a temporal dependence model for these errors to be able to produce realistic hourly MAP error series.

3. Use of Monte Carlo simulations of rainfall scenarios based on the calibrated error model and propagation of these scenarios into two selected lumped RR models.

The two selected RR models are modified versions of the GR4J model (Perrin et al., 2003) and of TOPMODEL (Beven and Kirby, 1979; Mathevet, 2005). Various catchment areas are considered to reveal a possible link between the sensitivity to MAP uncertainties and the considered catchment area.

The paper is structured as follows. The study area and data sets are presented in Sect. 2. The interpolation method and principles of the proposed error model are outlined in Sect. 3. The cross-validation approach and the error model validation results are presented in Sect. 4. Section 5 is devoted both to the propagation of the MAP errors into the RR models and to the interpretation and discussion of the results obtained. Conclusions drawn from the study are summarised in Sect. 6. 
Table 1. Main hydroclimatic characteristics of the three studied catchments $\left(\bar{P}:\right.$ mean annual precipitation ; $\bar{Q}:$ mean annual flow; $Q_{10}$ : 10-year specific flow).

\begin{tabular}{lrrrrrr}
\hline River & $\begin{array}{r}\text { Drainage } \\
\text { area }\left(\mathrm{km}^{2}\right)\end{array}$ & $\begin{array}{r}\text { Period } \\
\text { of record }\end{array}$ & $\begin{array}{r}\bar{P} \\
(\mathrm{~mm} / \mathrm{y})\end{array}$ & $\begin{array}{r}\bar{Q} \\
\left(\mathrm{~mm} / \mathrm{y},\left[\mathrm{m}^{3} / \mathrm{s}\right]\right)\end{array}$ & $\bar{Q} / \bar{P}$ & $\begin{array}{r}Q_{10} \\
\left(\mathrm{~m}^{3} / \mathrm{s} / \mathrm{km}^{2}\right)\end{array}$ \\
\hline Loire at Rieutord & 62 & $1983-2002$ & 1530 & $1420[2.7]$ & 0.90 & 5.6 \\
Lignon at Chambon & 139 & $1977-2003$ & 945 & $726[3.2]$ & 0.77 & 1.4 \\
Loire at Bas-en-Basset & 3234 & $1977-2003$ & 900 & $364[37.3]$ & 0.40 & 0.4 \\
\hline
\end{tabular}

\section{The study area and data}

The upper Loire River is located in the northern part of the Cevennes-Vivarais Hydro-Meteorological Observatory region (Delrieu, 2003; Delrieu et al., 2005). The catchment of the upper Loire River at Bas-en-Basset covers $3234 \mathrm{~km}^{2}$ (Fig. 1). It is an upland, mainly rural area with dominantly plutonic, metamorphic and locally volcanic bedrocks. The soils are relatively shallow (from a few centimeters to a few meters, on average less than one meter deep). The elevation of the catchment ranges from about 450 to $1700 \mathrm{~m}$ a.s.l.

The study area is exposed to various climatic influences. Mediterranean storms induce flash-floods that affect headwater catchments in the south-eastern part of the area. This explains the very high 10-year flood specific flow values of these catchments, which range from 0.4 to $5.6 \mathrm{~m}^{3} \mathrm{~s}^{-1} \mathrm{~km}^{-2}$ (Table 1). Conversely, the north-western part of the upper Loire river basin is influenced by a typical oceanic climate, with moderate flood events. Due to the altitudes and the mid-mountain climatic influence, snowfall and snowmelt may sometimes be non negligible elements of the water budget in the south-eastern part of the upper Loire. Nevertheless, they have little influence on the major flood events that predominantly occur in autumn and which are here the main concern. Consequently, in this study, no snowmelt routine is implemented in the tested RR models.

The density of the raingauge network has progressively increased over the years: the number of automatic raingauges has grown from six in 1977 to 40 at present. The automatic raingauge network now in operation, developed for flash flood forecasting purposes, is relatively dense (about $1 / 80 \mathrm{~km}^{2}$ ) if compared to the average density of automatic raingauges in France $\left(1 / 500 \mathrm{~km}^{2}\right)$. Moreover, the upper Loire hydrologic network of rain and stream gauges is considered to be among the best-maintained operational networks in France. A weather radar system, located in the North-West of the upper Loire catchment, has been in operation since 1996. But due to technical problems, such as the high elevation of the radar (1116 m a.s.l.), ground clutter, and masking effects caused by the surrounding trees and topography of the region, it has not yet been possible to use weather radar to estimate rainfall rates. Mean areal precipitation (MAP) estimations can therefore only rely on the raingauge network.

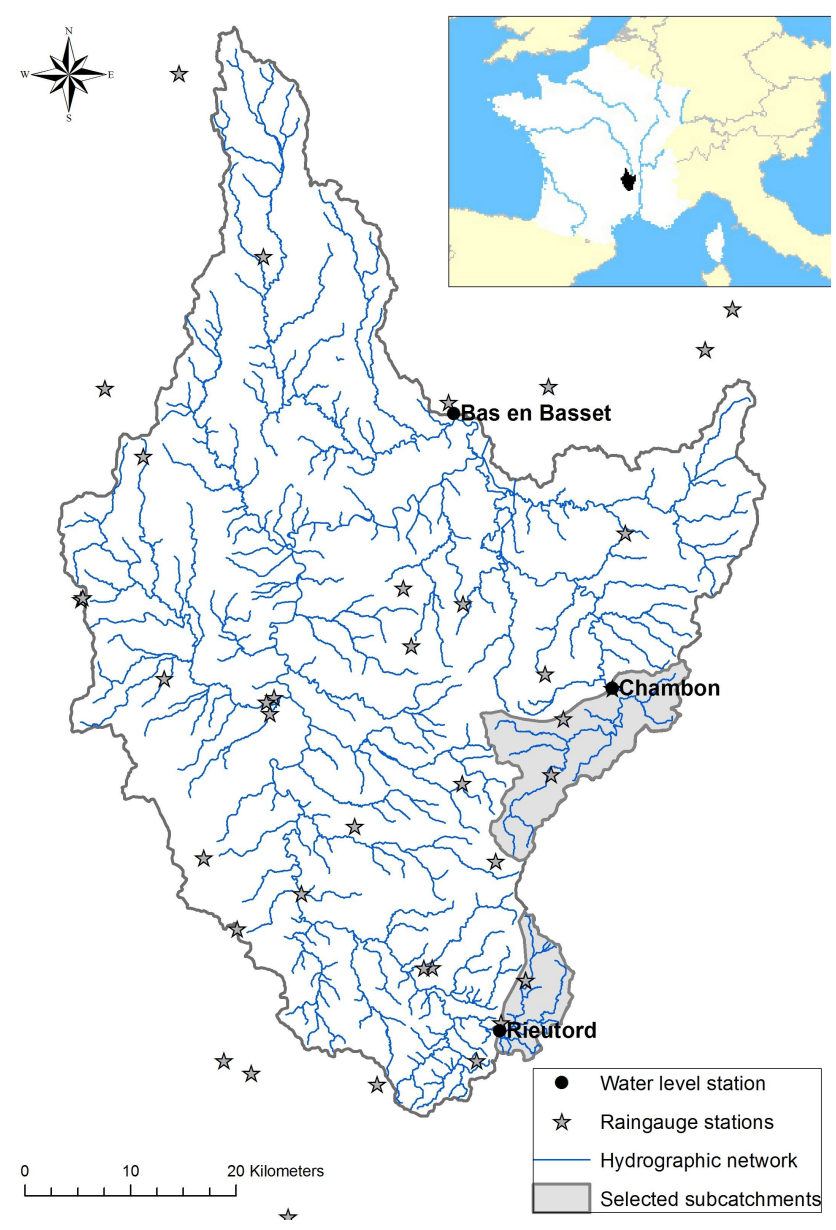

Fig. 1. The upper Loire river catchment at Bas-en-Basset $\left(3234 \mathrm{~km}^{2}\right)$ with two subcatchments shown in gray: the Loire river at Rieutord $\left(62 \mathrm{~km}^{2}\right)$ and the Lignon river at Chambon-sur-Lignon $\left(139 \mathrm{~km}^{2}\right)$. Raingauges stations indicated correspond to the hourly network available in 2003.

Three nested catchments have been selected for this study. This choice has been dictated by the quality and length of the available streamflow series (20 years for Rieutord, 27 years for both Chambon-sur-Lignon and Bas-en-Basset), their location in areas affected by flash floods, and the desire to cover a large range of catchment areas $(62,139$, and $3234 \mathrm{~km}^{2}$ ). Some intermediate-sized catchments are 
available but affected by dam management. The main characteristics of these three catchments are summarised in Table 1 .

\section{Methodology for estimating precipitation uncertain- ties}

\subsection{A geostatistical framework}

Geostatistical methods and especially kriging are now generally accepted as the most effective approaches to interpolate point rainfall measurements. These methods, and in particular "climatological" kriging, have been widely used and tested in the past and appear to deliver reasonable rainfall estimates, particularly in the case of sparse networks (Lebel et al., 1987; Haberlandt, 2007).

Kriging is basically a linear interpolation approach. The estimated values of point rainfall amounts $P_{t}\left(\mathrm{x}_{0}\right)$ at any location $x_{0}$ as well as mean areal precipitation $\operatorname{MAP}_{t}(S)$ over a given domain $S$ (of area $S \mathrm{~km}^{2}$ ) are, at any time $t$, considered as linear combinations of the point rainfall amounts $P_{t, j}$ measured by the raingauges of the surrounding raingauge network (Eqs. 1 and 2) :

$P_{t}\left(x_{0}\right)=\sum_{j=1}^{n} \mu_{t, j} P_{t, j}+\varepsilon_{t}\left(x_{0}\right)$

$\operatorname{MAP}_{t}(S)=\sum_{j=1}^{n} \lambda_{t, j} P_{t, j}+\varepsilon_{t}(S)$

with $n$ the number of the considered raingauges, $\varepsilon_{t}\left(x_{0}\right)$ and $\varepsilon_{t}(S)$ the estimation errors of $P_{t}\left(x_{0}\right)$ and $\operatorname{MAP}_{t}(S)$. The value of the weights $\mu_{t, j}$ and $\lambda_{t, j}$ are adjusted to minimise the variance of the errors $\varepsilon_{t}\left(x_{0}\right)$ and $\varepsilon_{t}(S)$ given some assumptions concerning the spatial structure of the rainfall fields. Kriging is flexible in the sense that a large variety of hypotheses about this spatial structure can be accounted for: observed anisotropy of rainfall fields, general trends linked to the relief for instance, spatial rainfall structure varying with seasons or rainfall types, etc. Nevertheless, ordinary kriging assumptions are generally selected for interpolating rainfall rate fields (Chen et al., 2008), especially when small time steps are considered. Moreover, accounting for anisotropy (Lebel et al., 1987; Haberlandt, 2007) or trends (KiefferWeisse and Bois, 2002) does not generally significantly improve the interpolation accuracy, in particular in the case of short time steps. The kriging was performed in a standardised mode, which means that instead of working on the absolute values $\left(P_{t}\left(x_{0}\right)\right.$ or $\left.\mathrm{MAP}_{t}(S)\right)$, these values are standardised by the variance of the field $S D_{t}$ (empirically computed on a window covering the largest of the study catchment). In that case the normalised field variance, and the sill of the variogram, is brought to 1 . Next the following assumptions were used : (a) the spatial correlation structure of the rainfall intensities divided by the estimated standard deviation of the rainfall field $S D_{t}$ (normalised rainfall intensities and normalised variogram or correlogram) is the same for every time step and rainfall events (hypothesis for climatological kriging), (b) the variogram is isotropic, (c) the possible influence of altitude and exposition is neglected for the interpolation (i.e. the interpolation is only based on inter-station distances), (d) a spherical variogram (Eq. 3) is used.

$$
\gamma(h, \alpha, \beta)=\left\{\begin{aligned}
& \alpha \cdot\left[\frac{3}{2} \cdot \frac{h}{\beta}-\frac{1}{2} \cdot\left(\frac{h}{\beta}\right)^{3}\right] \\
& \alpha \leq \beta \\
& h>\beta
\end{aligned}\right.
$$

where $\gamma$ is the semi-variogram, $h$ is the distance between two locations (inter-distance), $\alpha$ is the sill (equal to unity in the case of climatological kriging, given the normalisation with rainfall field variance) and $\beta$ is the range of the variogram (in $\mathrm{km})$.

The main adjustment factor of this kriging model is the variogram shape taken here as spherical), and particularly its range $\beta$. Information from previous works conducted in the same region (Lebel et al., 1987) led to the calibration of a relation between the time step considered and the range $\beta$ for a spherical variogram (Eq. 4).

$\beta(k m)=25 \Delta t^{0.3}$

where $\beta$ is the range (in $\mathrm{km}$ ) and $\Delta t$ is the time step (in hours) of the rainfall data. According to this relationship, the range of the variogram of hourly rain rates is set equal to $25 \mathrm{~km}$. This estimate of range appears to be well suited to the upper Loire river area when plotting empirical variograms.

Note that since with these hypotheses, the weights $\lambda$ change only if the neighbourhood used for kriging and therefore the available network of stations changes. It must also be mentioned that the estimation residual for a point normalised value $p_{t}\left(x_{0}\right)$ is at the maximum (when $x_{0}$ far from every raingauge) equal to its field variance $S D_{t}^{2}$ set to 1 . For the absolute value $P_{t}\left(x_{0}\right)=p_{t}\left(x_{0}\right) \times S D t$ rainfall field standard deviation, its residual is also rescaled by this rainfall field standard deviation.

\subsection{The rainfall interpolation errors and the error model}

\subsubsection{Model for interpolation errors}

Interpolation models based on kriging deliver not only interpolated values but also an estimate of the associated uncertainty through the computation of a theoretical interpolation error variance $\sigma^{2}$ or a standard deviation $\sigma$, also named kriging standard deviation (Eqs. 5 and 6).

$$
\begin{gathered}
\sigma_{t}^{2}\left(x_{0}\right)=E\left\{\left(\varepsilon_{t}\left(x_{0}\right)\right)^{2}\right\} \\
\sigma_{t}^{2}(S)=E\left\{\left(\varepsilon_{t}(S)\right)^{2}\right\}
\end{gathered}
$$


When a climatological variogram $\bar{\gamma}_{i j}$ is used between points $x_{i}$ and $x_{j}$ (inter-distance $d_{i j}$ ), the weights $\mu_{t, j}$ and $\lambda_{t, j}$ are supposed constant over the time if the raingauge network remains unchanged. The kriging interpolation errors may then be normalised by the standard deviation of rainfall field $S D_{t}$. Since the normalised variogram is supposed to be constant, the resulting normalised standard deviation $\bar{\sigma}_{t}$ depends then only on the topology on the raingauge network, i.e. on the configuration (distance, direction) and on the number and configuration of the surrounding raingauges available at time $t$. Thus it may be constant over several time steps (Lebel et al., 1987) and constant over the whole period in case of a stationary network (no evolution of network and no failure in data collection).

$\bar{\sigma}\left(x_{0}\right)=\sigma_{t}\left(x_{0}\right) / S D_{t}$

$\bar{\sigma}(S)=\sigma_{t}(S) / S D_{t}$

Errors $\bar{\sigma}\left(x_{0}\right)$ and $\bar{\sigma}(S)$ (Eqs. 7 and 8) can be minimised by the method of Lagrange multipliers. The values $\xi\left(x_{0}\right)$ and $\xi(S)$ are used to impose unbiased rainfall estimates : $\sum_{i=1}^{n} \mu_{i}=1$ and $\sum_{i=1}^{n} \lambda_{i}=1$ (Eqs. 9 and 10).

$\xi\left(x_{0}\right)=\bar{\gamma}_{i 0}-\sum_{j=1}^{n} \mu_{j} \bar{\gamma}_{i j}, \forall i$

$\xi(S)=\bar{\gamma}_{i S}-\sum_{j=1}^{n} \lambda_{j} \bar{\gamma}_{i j}, \forall i$

with $\bar{\gamma}_{i, 0}$ the normalised semi-variogram function depending on the distance $h$ between the locations $i$ and $x_{0}, \bar{\gamma}_{i S}$ the average value of the semivariogram between the raingauge $x_{i}$ and any point of the surface $S$ (Eq. 11) and $\bar{\gamma}_{S S}$ the average value of the semivariogram between the points of the surface $S$ (Eq. 12).

$\bar{\gamma}_{i S}=\frac{1}{S} \int_{S} \bar{\gamma}\left(x_{i}-x\right) d x$

$\bar{\gamma}_{S S}=\frac{1}{S^{2}} \int_{S} \int_{S} \bar{\gamma}\left(x-x^{\prime}\right) d x d x^{\prime}$

This ordinary kriging method with a climatological variogram yields:

$\bar{\sigma}^{2}\left(x_{0}\right)=\sum_{i=1}^{n} \mu_{i} \bar{\gamma}_{i, 0}+\xi\left(x_{o}\right)$

$\bar{\sigma}^{2}(S)=\sum_{i=1}^{n} \lambda_{i} \bar{\gamma}_{i, S}-\bar{\gamma}_{S S}+\xi(S)$

The model for normalised interpolation errors proposed here assumes that these errors in estimates of both point and areal hourly precipitations, follow a zero-mean Gaussian distribution whose standard deviation is $\bar{\sigma}_{t}$ (depending on the available raingauge network at time $t)$. A normalised standard deviation $\bar{\sigma}\left(x_{0}\right)$ (or $\bar{\sigma}(S)$ ) lower than 0.5 means that more than $75 \%$ of normalised rainfall field variance at the location $x_{0}$ (respectively on the area) is explained (kriging standard deviation $=0.5$; then kriging variance $=0.5^{2}=0.25$; explained variance $=1-0.25=0.75$ ). When it is lower than 0.7 , more than $50 \%$ of the observed signal is explained.

In Fig. 2, the distribution of theoretical normalised kriging standard deviation $\bar{\sigma}\left(x_{0}\right)$ for point estimates is mapped for interpolated daily and hourly rainfall rates for the upper Loire river catchment with the available network in the year 2003. It appears that for hourly rain rates, the theoretical point kriging standard deviation is higher than 0.7 on more than $50 \%$ of the study area. In other words, the spatial interpolation explains less than $50 \%$ of the variance of the observed signal on more than half of the area.

Likewise, Fig. 3 shows the evolution over time of the proportion of the upper Loire area where $\bar{\sigma}\left(x_{0}\right)$ for point rainfall estimates is lower than 0.5 or 0.7 (more than $75 \%$ or $50 \%$ of the variance of the signal is explained). Despite the increase of the density of the raingauge network for the last 20 years, from 1 tipping bucket raingauge for $500 \mathrm{~km}^{2}$ to 1 for $80 \mathrm{~km}^{2}$, high uncertainties remain on point rainfall rates estimated through spatial interpolation in many parts of the region, especially when short time steps are considered (hourly rainfall rates). In other words, poor or even no information on the hourly rain rates is available on the majority of the area. Nevertheless, the situation for MAP estimation uncertainties is generally less dramatic due to averaging especially when large time steps and/or large areas are considered (Villarini et al., 2008). For instance, in year 2003, the kriging standard deviation of MAP $\bar{\sigma}(S)$ with all raingauges available is 0.15 for the MAP computed on the catchment of Loire at Basen-Basset, 0.24 for catchment at Chambon-sur-Lignon and 0.32 at Rieutord. These values result in explained variances of $0.98,0.94$ and 0.90 respectively, increasing with area as expected.

\subsubsection{Modelling temporal structure of interpolation errors}

Possible time dependence between successive interpolation errors must be considered in an error model to produce realistic error time series. At a given time, interpolation errors are due to the spatial sampling that may not capture some features of the rainfall field: typically over or under-estimations linked to the relative position of intense rainfall cells and raingauges. If the time step is short according to the displacement of the cells, the same type of error may affect several successive estimates. Interpolation errors for both point and areal estimates may be dependent in time. 

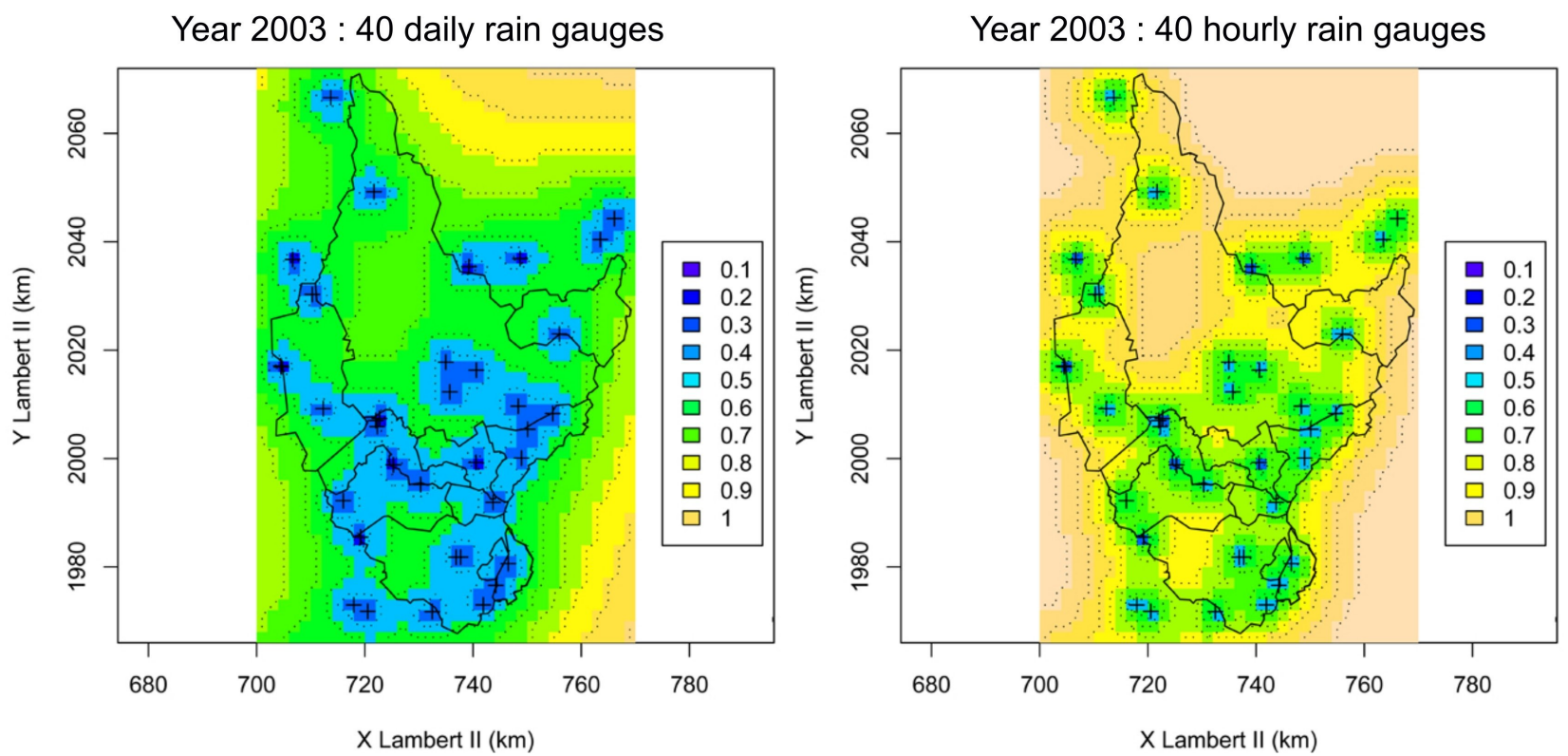

Fig. 2. Maps of theoretical normalised kriging standard deviation $(\bar{\sigma})$ for the network over the upper Loire river catchment area available in 2003 and for two time step: daily time step (left) and hourly time step (right)

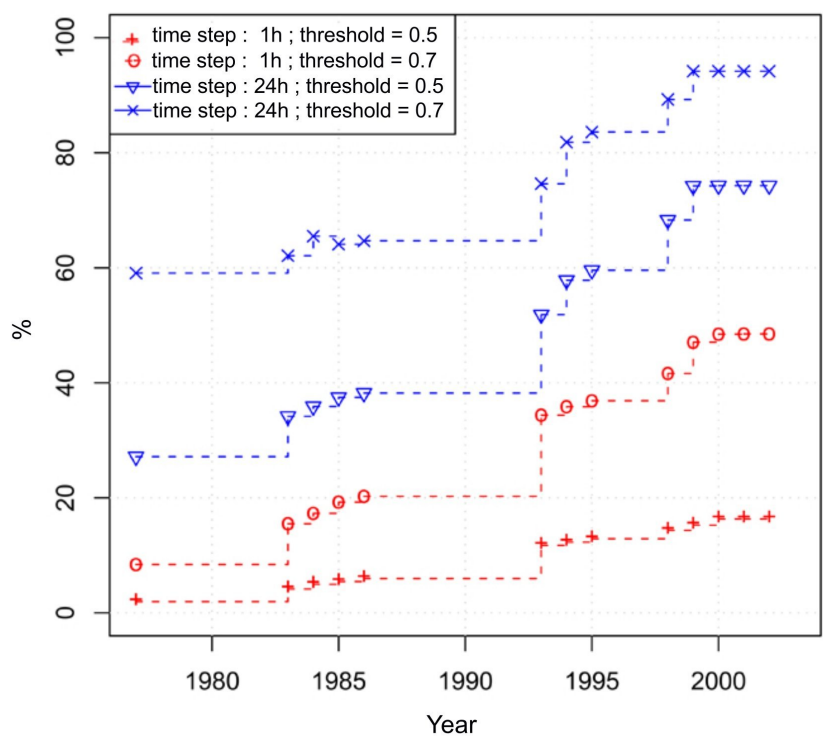

Fig. 3. Evolution of the percentage of the upper Loire river area where the theoretical normalised kriging standard deviation is lower than 0.5 (75\% of variance is explained) or 0.7 (50\% of variance is explained) for the cases of both daily and hourly time step.

The dependence in time between hourly rain rate interpolation errors will be analysed using the available raingauge measurements. Raingauges are removed in turn from the network and the rainfall intensities computed at the corresponding location using the remaining network (cross validation detailed in Sect. 4.1). The comparison of the measured and computed intensities delivers series of hourly point rainfall estimation errors. The temporal structure of these series can be then examined and simulated.

A linear autoregressive model has been first tested to reproduce the observed dependence in time between these errors (Eq. 15).

$\eta_{t+1}=\rho \cdot \eta_{t}+\sqrt{\left(1-\rho^{2}\right)} \cdot \bar{\sigma}_{t} \cdot v_{t+1}$

where $\eta_{t}$ is the normalised interpolation error at time step $t$, $\rho$ is the autocorrelation coefficient between two successive errors, $\bar{\sigma}_{t}$ is the theoretical standard deviation of the interpolation normalised error distribution and $v_{t+1}$ a random variable with a standard normal distribution. Note that, the proposed model does not affect the standard deviation $\bar{\sigma}_{t}$ of the normalised interpolation errors. $\bar{\sigma}_{t}$ does only change if the raingauge network structure changes, which rarely happens within a rainfall event.

This model will be calibrated, tested and validated for point rainfall estimates. Without reference values for MAPs, it is not possible to conduct the same tests and validations for the errors on MAPs. As for the spatial interpolation model, the evaluation of its adequacy can only rely on point rainfall validation.

Due to the linearity of both the kriging interpolation model and the autoregressive (AR) model, the selected AR model for point rainfall errors will also hold for MAP errors provided that its parameters - i.e. the autocorrelation coefficient - are independent of location. In Eq. $15, \bar{\sigma}_{t}$ is then considered equal to $\bar{\sigma}_{t, S}$ (MAP estimate) rather than to $\bar{\sigma}_{t, x_{0}}$ (point 
estimate). One of the goals of the validation of the AR error model will therefore also be to verify the stability of $\rho$. Other rainfall estimation error models taking into account the dependence in time have been suggested (Retnam and Williams, 1988; Andrieu et al., 2003), but the proposed MAP estimation error model has the advantage of being simple, robust and suited to the observed data, as will be shown in the coming section.

It is important to mention that there is no constraint on the value of the interpolation error in the proposed model (Gaussian distribution). The addition of a randomnly drawn error to an interpolated intensity may therefore provide negative intensity estimates. The analysis of the Monte Carlo simulations conducted (see the next section) revealed that 6 to $7 \%$ of the simulated intensities are negative accounting for 2 to $3 \%$ of the total rainfall amounts. The percentage depends on the location or catchment area considered. Negative values are only generated for low intensities; they are generally only slightly negative and do therefore not significantly affect the major rainfall events of the studied series. For the purpose of rainfall-runoff simulation, these negative values were set equal to zero.

\section{Step-by-step validation of the error model: example on the upper Loire river area}

\subsection{Validation of hourly precipitation error model}

The validation of the kriging interpolation model has two objectives: (a) first to verify if the interpolated values can be considered as satisfactory and especially if they appear to be unbiased and (b) to verify the theoretical interpolation normalised error model. The related questions are the following: Are the observed estimation error variances consistent with the theoretical variances? Are the distributions of the interpolation errors well approximated by Gaussian distributions with zero mean? In other words, are these distributions fully determined by their standard deviation $\bar{\sigma}$ ?

The empirical point rainfall interpolation error at point $x_{0}$ for the time step $t$ can be defined as the difference between $\widehat{P}_{t}\left(x_{0}\right)$, the estimated value at this point based on interpolation of values of the surrounding raingauges using the chosen variogram and $P_{t}\left(x_{0}\right)$, the "real" - measured if there is a raingauge reading available, unknown if not - value of precipitation at this point $x_{0}$ at time $t$.

A cross-validation approach was first conducted to check the consistency between theoretical (i.e. given by the proposed error model) and observed (i.e. difference between measured and interpolated rainfall rate values) hourly point rainfall estimated normalised standard deviations of error. It consists of removing in turn one raingauge from the network to compare the measured and interpolated rain rates at the specific site. Then the distribution of theoretical errors (obtained from the error model) can be compared with
Table 2. Percentage of computed interpolation errors contained in various theoretical confidence intervals for four raingauges. See also Fig. 4.

\begin{tabular}{lrrr}
\hline Raingauge & $68 \% \mathrm{CI}( \pm \sigma)$ & $95 \% \mathrm{CI}( \pm 2 \sigma)$ & $99.7 \% \mathrm{CI}( \pm 3 \sigma)$ \\
\hline Fay & 53.5 & 77.3 & 89.8 \\
Goudet & 59.4 & 80.7 & 90.3 \\
Machabert & 63.1 & 84.8 & 93.4 \\
Mazet & 59.8 & 81.8 & 91.0 \\
\hline
\end{tabular}

the distributions of empirical errors (differences between observations and computed values). The validation can only be performed for point rainfall estimates, i.e. the only estimates for which reference values (observations) are available for the computation of estimation errors. This point crossvalidation was carried out on the 40 raingauges available in this area.

A MAP is a weighted average of the linearly correlated point rainfall estimates. Therefore, if the hourly point rainfall estimation errors appear to follow a zero-mean Gaussian law with the theoretical kriging standard deviation at any location of the considered area, the hourly MAP estimation errors will also follow a zero-mean Gaussian law with the theoretical kriging standard deviation.

Table 2 and Fig. 4 compare the theoretical zero-mean Gaussian normalised error distributions and the observed hourly normalised rainfall interpolation error distributions for a representative selection of four of the 40 validation raingauges, distributed over the upper Loire river catchment area. First, a relatively good correspondence between empirical and theoretical distributions can be observed. The results obtained for other gauges and for other periods - i.e. other raingauge network structures, with a different $\bar{\sigma}-$ are similar. These results confirm that the selected range of the variogram is well suited to the upper Loire river area and that the observed normalised error distributions can be well approximated by a zero-mean, Gaussian type distribution. Large normalised error values, especially negative errors corresponding to an underestimation of the rainfall intensity, are nevertheless over-represented in the empirical validation set if compared to the theoretical Gaussian distribution. This is particularly noticeable in Table 2, where proportions of estimated values contained in the theoretical confidence intervals appear to be lower than the theoretical proportions. This is a common feature of rainfall interpolation techniques that smooth the rainfall fields and tend to underestimate extreme local values (Fig. 5).

Considering the simplicity of the interpolation model (linear interpolation with one parameter which is the variogram range) and of the error model (Gaussian error distributions), the validation results, still far from perfect, are nevertheless satisfactory. Of course, the match between observed and theoretical point rainfall estimation normalised errors is never perfect. But a good agreement at every validation gauge 


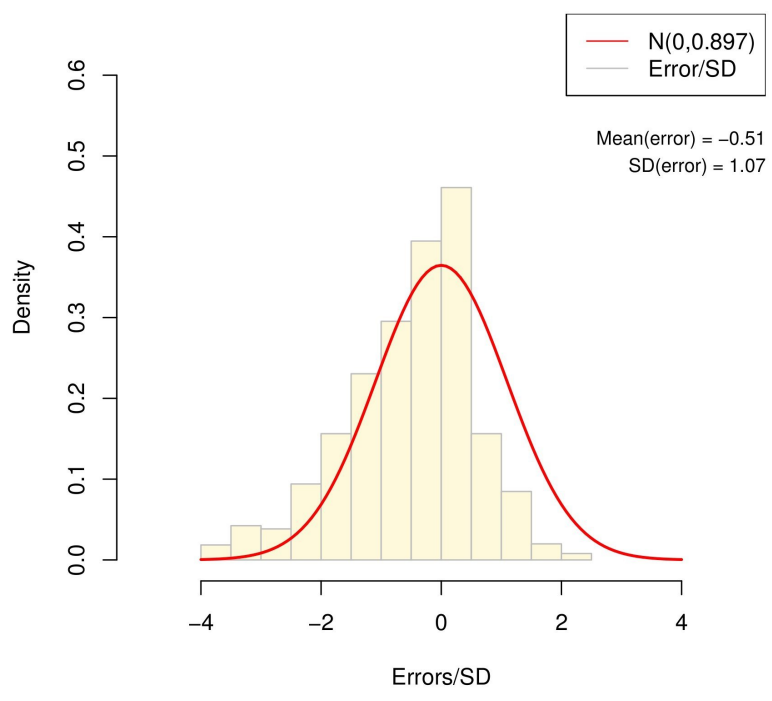

Fay

Theorical distribution vs Kriging with Sigma(k)=0.718 n=1255

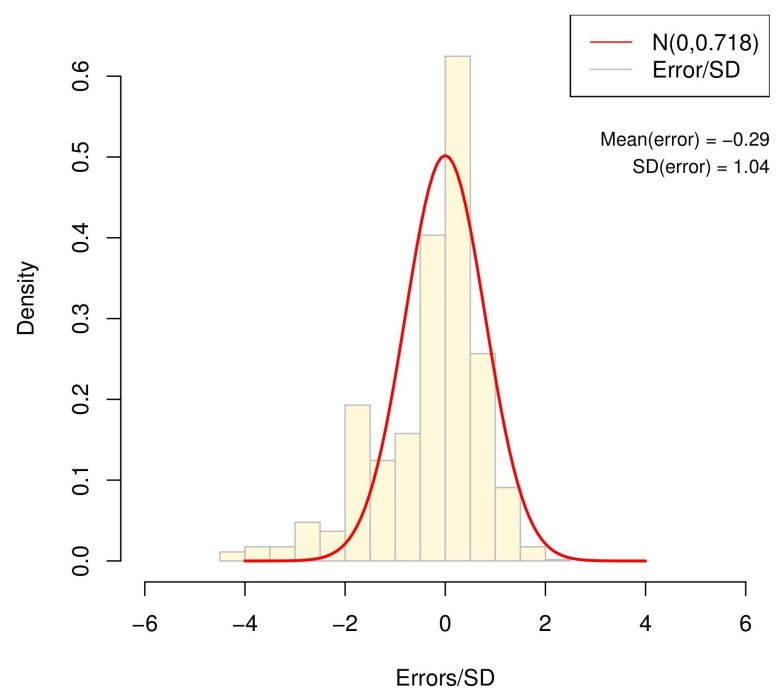

Machabert

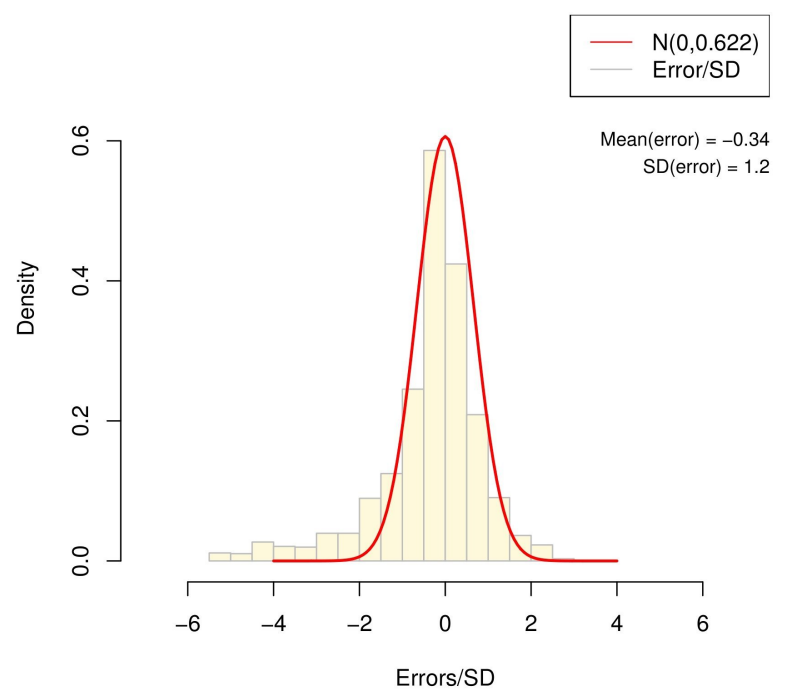

Goudet

Theorical distribution vs Kriging with Sigma(k)=0.785 $n=878$

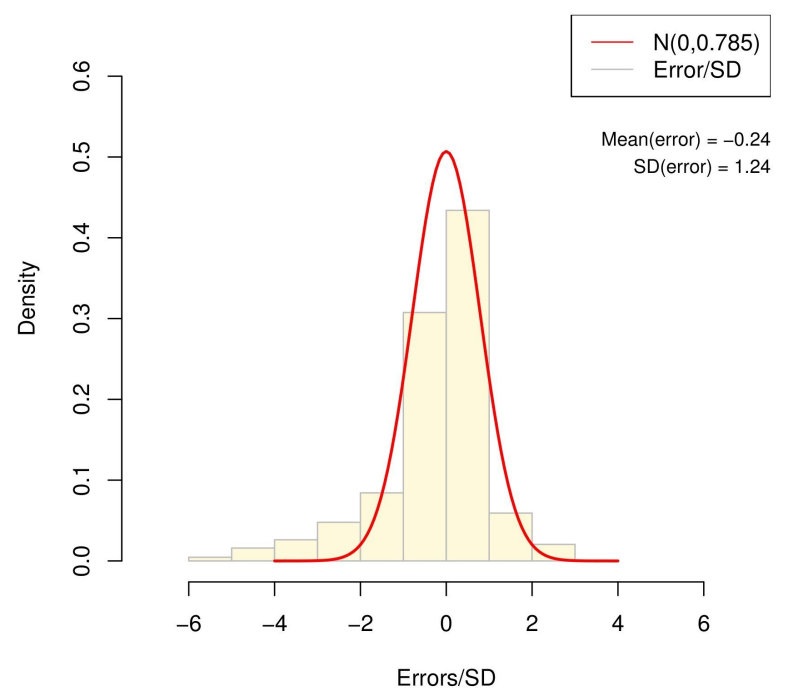

Mazet

Fig. 4. Comparison between the distributions of theoretical and empirical (obtained with cross-validation and represented as histograms) normalised rainfall estimation errors for four rain gauges of the network. See also Table 2.

will ensure that the theoretical MAP Gaussian normalised error model will deliver realistic error ranges and distributions. The higher density of largely underestimated values in the observed distributions, if compared to the theoretical Gaussian one, explains both the bias and the higher standard deviation of the empirical error distributions. Overall, the Gaussian theoretical interpolation error model gives a reliable image of the kriging error distributions for interpolated hourly rain rates. It slightly underestimates the error ranges and percentiles and hence will tend to underestimate the effect of these errors on RR model outputs.
Figure 5 also reveals another feature of the proposed error model. The standard deviation of the interpolation error depends of the standard deviation of the rainfall field $S D_{t}$. It is fluctuating but shows a general tendency to increase when the measured rainfall intensity increases.

\subsection{Validation of temporal dependence model}

The simplest way to check if time dependence is correctly accounted for by the proposed model consists of comparing theoretical (simulated) and observed (empirical) estimation 
Table 3. Standard deviations of the empirical normalised error on mean intensities over various durations: observed (normalised errors obtained with the cross validation) and simulated with timedependent error model. A constant correlation coefficient is equal to 0.6 . See also Fig. 6 .

\begin{tabular}{lcccccccc}
\hline $\begin{array}{l}\text { Time step } \\
\text { (hours) }\end{array}$ & \multicolumn{2}{c}{ Fay } & \multicolumn{2}{c}{ Goudet } & \multicolumn{2}{c}{ Machabert } & \multicolumn{2}{c}{ Mazet } \\
& Obs. & Sim. & Obs. & Sim. & Obs. & Sim. & Obs. & Sim. \\
\hline 1 & 1.05 & 0.74 & 0.76 & 0.66 & 0.76 & 0.77 & 0.97 & 0.69 \\
2 & 0.95 & 0.65 & 0.66 & 0.58 & 0.69 & 0.68 & 0.72 & 0.61 \\
4 & 0.79 & 0.54 & 0.55 & 0.49 & 0.55 & 0.56 & 0.57 & 0.51 \\
6 & 0.70 & 0.47 & 0.49 & 0.42 & 0.48 & 0.49 & 0.47 & 0.44 \\
12 & 0.58 & 0.36 & 0.39 & 0.33 & 0.40 & 0.38 & 0.36 & 0.34 \\
24 & 0.49 & 0.26 & 0.29 & 0.24 & 0.32 & 0.27 & 0.28 & 0.24 \\
\hline
\end{tabular}

errors for rainfall amounts accumulated over several time steps. As far as the temporal dependence model is concerned, the first objective of the cross-validation is a comparison of theoretical and observed estimation error distributions for point rainfall amounts accumulated over a large range of time steps with an autocorrelation coefficient $\rho$ estimated at each location. The second objective is to determine if this coefficient $\rho$ is not too dependent on location, in order to be able to extrapolate the model to MAP errors.

The distributions of modelled and empirical normalised interpolation errors for rainfall amounts, accumulated over various time steps, are first compared to adjust the correlation coefficient and assess the reliability of the proposed temporal dependence model. Such a comparison is shown in Fig. 6 for the Goudet validation raingauge. Monte Carlo runs based on Eq. 15 are used to simulate series of hourly rain rate interpolation errors and then to build their distribution for various accumulation durhessations. The impact of the correlation coefficient on the error series structure and especially on the error distributions of rainfall amounts accumulated over more than one hour is clearly noticeable in Fig. 6. The comparison with the distributions of observed errors clearly reveals the necessity of taking into account the time-dependence of interpolation errors and the adequacy of the proposed time-dependence model. This adequacy is confirmed for other validation raingauges (Table 3). In most cases, the proposed model reproduces the evolution of the interpolation error distributions for rainfall amounts accumulated over a large range of time steps and for various locations of the raingauge network (not shown). Moreover, the correlation coefficient appears not to be too much dependent on the location in space, which is another very positive result of this cross-validation. Even if far from perfect, the proposed error model appears to be able to generate reliable point rainfall estimation error series. Although it could not be directly verified, according to the properties of the model presented in the previous section and to the stability of the temporal correlation coefficient, it can be assume that the proposed model certainly also provides reliable MAP estimation error series.

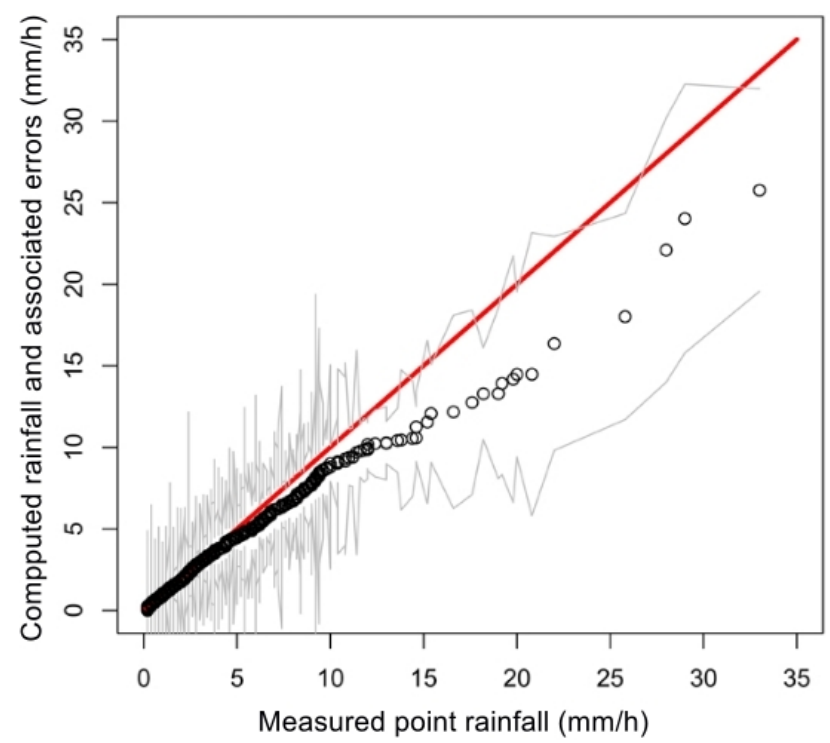

Fig. 5. Point hourly precipitations ranked in ascending order versus corresponding interpolated values (cross validation) plus or minus computed standard deviation (grey lines). Mazet rain gauge.

\section{Propagation of rainfall uncertainties through rainfall-runoff models}

The interpolation error model is now selected and at least verified on point values since its validity for MAP could not be completely tested. Monte Carlo runs were then implemented to simulate different scenarios of possible hourly MAP series corresponding to the available point rainfall measurements. These scenarios are then fed into calibrated RR models to evaluate the impact of rainfall estimation uncertainties on RR simulation results and hence on RR modelling efficiency.

\subsection{Methodology}

\subsubsection{Rainfall-runoff modelling}

The choice of adapted RR models is not the focus of the present study. A large body of scientific literature has been devoted to this question. The authors came to the conclusion that the data sets routinely available in hydrology support the development of models with only limited complexity - i.e. the calibration of models with a limited number of parameters, typically 4 to 8 (Jakeman and Hornberger, 1993; Perrin et al., 2001).

For these reasons, it has been decided to use robust lumped conceptual RR models run on a continuous basis. Based on both, the available rainfall data and the time to peak of the considered catchments - between 3 and $18 \mathrm{~h} \mathrm{-,}$, an hourly time step was selected for the computations. An automatic local optimisation multi-start algorithm is used for the calibration of the models (Edijatno et al., 1999; Mathevet, 2005). It is based on a gradient search procedure to evolve step by 

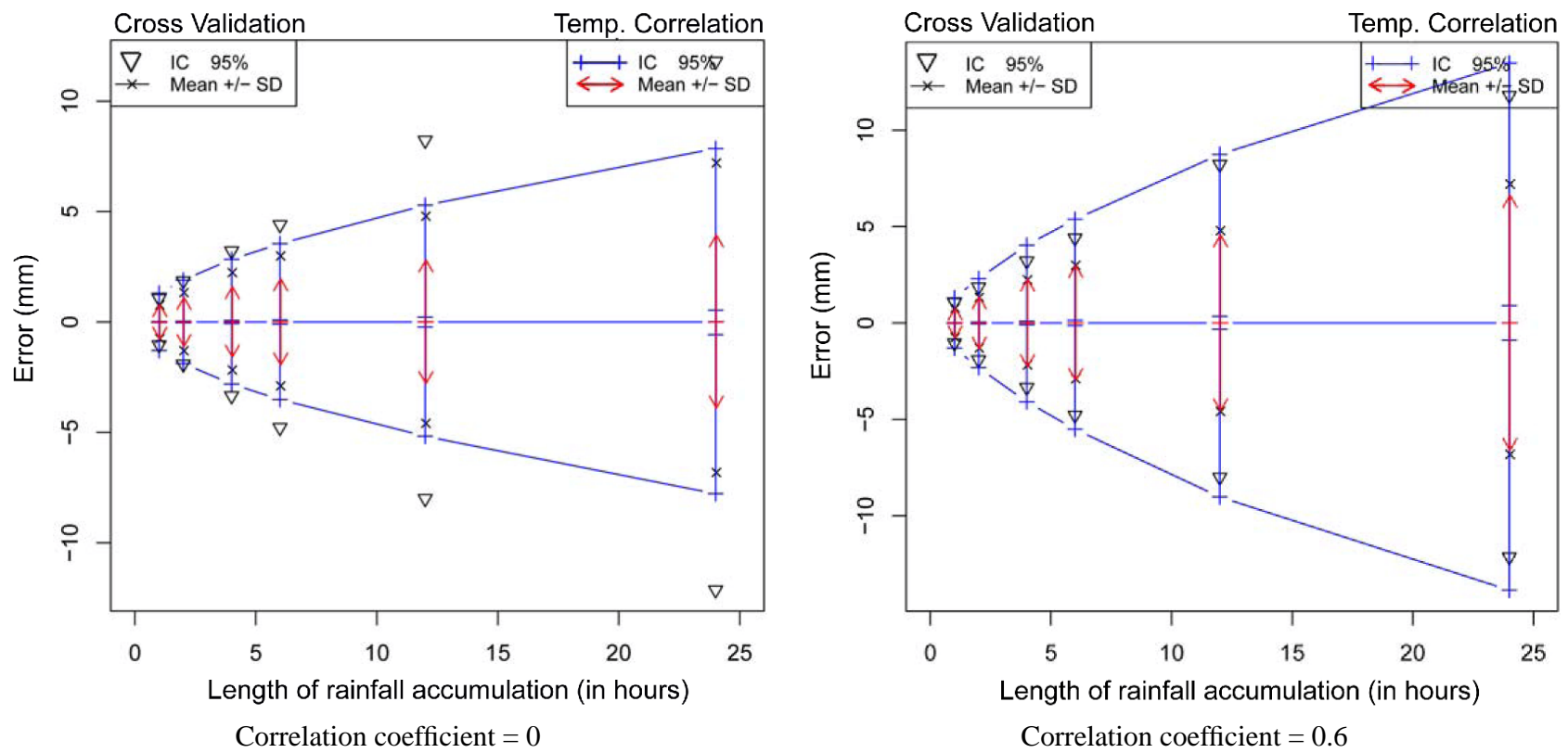

Fig. 6. Comparison of characteristics of distribution of simulated (with the AR error model, left: no temporal dependence; right: temporal dependence with a correlation of 0.6) interpolation errors (red arrows for mean \pm standard deviation ; blue " + " for 2.5 and 97.5 percentiles) accumulated over 1 to $24 \mathrm{~h}$ at Goudet raingauge with those of observed interpolation errors obtained with a cross validation process (black crosses " $x$ " for mean \pm theoretical standard deviation; black triangles for 2.5 and 97.5 percentiles).

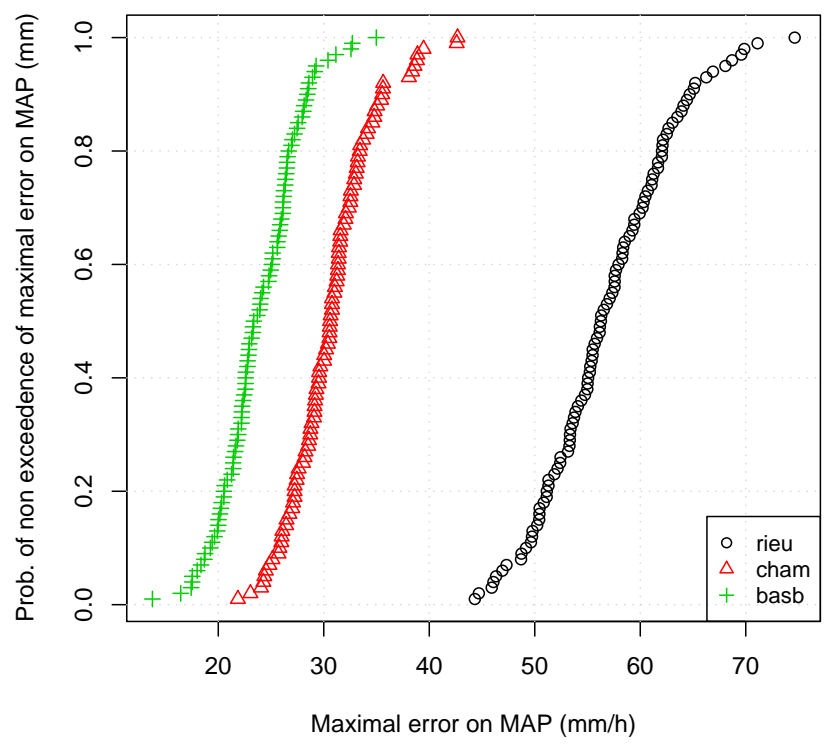

Fig. 7. Distribution of highest errors on MAP generated for each one of 100 scenarios and for each one of the three catchments of the upper Loire river $\left(\right.$ rieu $=$ Rieutord $\left(62 \mathrm{~km}^{2}\right)$; cham=Chambon-surLignon $\left(139 \mathrm{~km}^{2}\right)$; basb=Bas-en-Basset $\left(3234 \mathrm{~km}^{2}\right)$ )

step in the parameter space towards the optimum parameter values, corresponding to a maximisation of the objective function used. The selected objective function is the stan- dard Nash and Sutcliffe (1970) efficiency on streamflow values (Eq. 16). A split sample test procedure (Klemeš, 1986) is used to evaluate the performances of the models. The test consists of dividing the total period of the available data set into sub-sets. One is used for the calibration of the parameters and the others for the evaluation of the model performances in validation mode. The periods can be exchanged to multiply the number of validation tests. The Nash-Sutcliffe efficiencies obtained on the validation data sets are considered in order to evaluate the performances of the models.

$\mathrm{NSE}=1-\frac{\sum_{i=1}^{n}\left(Q_{S}\left(t_{i}\right)-Q_{o}\left(t_{i}\right)\right)^{2}}{\sum_{i=1}^{n}\left(Q_{o}\left(t_{i}\right)-\bar{Q}_{o}\left(t_{i}\right)\right)^{2}}$

where $Q_{s}\left(t_{i}\right)$ and $Q_{o}\left(t_{i}\right)$ are the simulated and observed streamflows at time step $i, n$ is the number of time steps in the period, and $\bar{Q}_{o}\left(t_{i}\right)$ is the mean observed streamflow during this period. This Nash-Sutcliffe efficiency criterion takes its values in the interval $[-\infty, 1]$.

The four-parameter GR4J model and the modified eightparameter TOPMO model (Perrin et al., 2003; Mathevet, 2005) based on Topmodel (Beven and Kirby, 1979), have been selected to study the influence of MAP interpolation uncertainties. A comparison with other RR models on the upper Loire river data set has shown that these two models had on average the best performances (Moulin, 2007). 

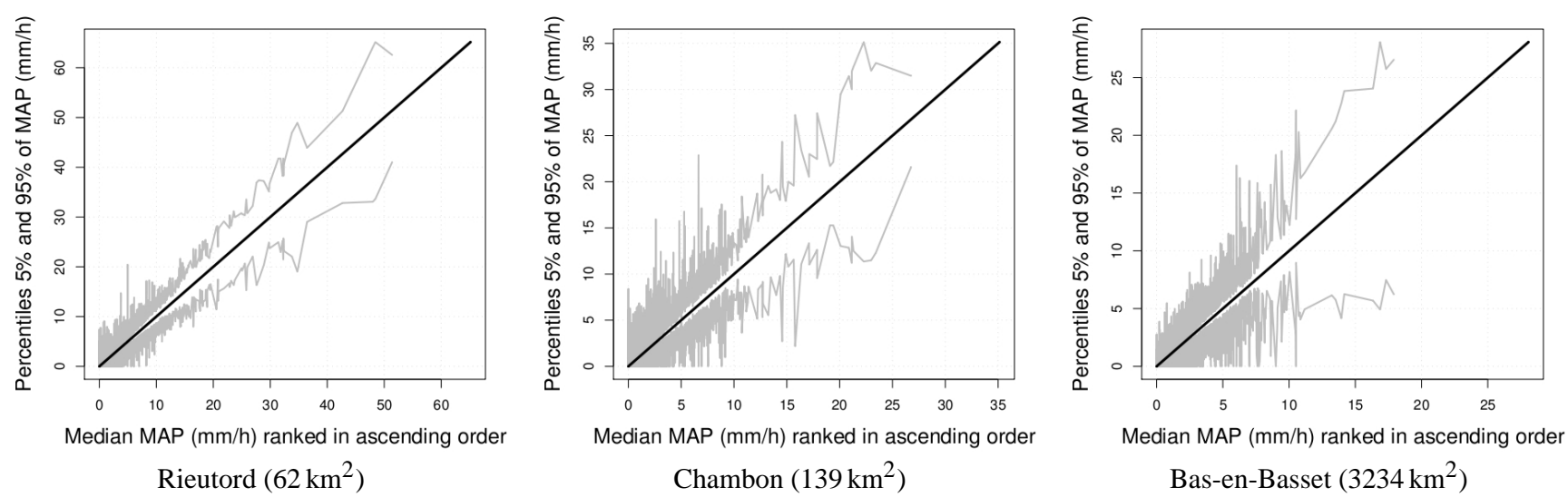

Fig. 8. Percentiles of uncertainty on MAP for Rieutord (left), Chambon-sur-Lignon (center) and Bas-en-Basset (right).

\subsubsection{Simulated rainfall scenarios and their properties}

To assess the impact of MAP uncertainties on streamflow simulations, Monte-Carlo simulations of errors added to the historical rainfall observations were conducted: 100 "possible" scenarios of MAP were generated with the above defined time-dependent error model for MAPs. These scenarios were then used as input to the RR models. Figure 7 presents the ranked highest simulated MAP errors for each of the 100 scenarios. The range and statistical distributions of these errors appear to vary depending on the catchment, and especially on its area, in a complex way linked both to the spatial and temporal dependencies and to the structure of the raingauge network. The maximum simulated MAPs and hence MAP error values affect the smaller catchments as illustrated in Figs. 7 and 8. This is due to the smoothing effect related to averaging that increases as the catchment area grows and tends to reduce the variance of the computed MAPs. Another important and less obvious result appears in Fig. 8: the relative errors (divided by either measured or median values) of estimated hourly MAPs have a tendency to increase with the catchment area. The ratio between the maximum computed MAP (about $50 \mathrm{~mm} / \mathrm{h}$ ) at Rieutord and the width of its estimated $90 \%$ confidence interval (about $20 \mathrm{~mm} / \mathrm{h}$ ) is of $40 \%$. It is close to $50 \%$ for the Chambon-sur-Lignon catchment (respectively $28 \mathrm{~mm} / \mathrm{h}$ and $14 \mathrm{~mm} / \mathrm{h}$ ) and to $100 \%$ for the Bas-en-Basset catchment (resp. $18 \mathrm{~mm} / \mathrm{h}$ and $18 \mathrm{~mm} / \mathrm{h}$ ). This tendency is observed for all the MAP quantiles. To summarise, absolute errors on MAPs decrease while relative errors on MAPs increase when the considered area increases. Apparently MAP errors are less affected by the smoothing effect due to averaging than the MAPs themselves.

The consequences on simulated peak streamflows are difficult to anticipate and will therefore be tested through numerical simulations. If the RR models were linear and if the RR relation was independent of the scale, the results would be similar for simulated streamflow relative errors (i.e. higher relative errors for larger catchments). But the RR relation is non-linear ; its smoothing or amplification effect on input errors may depend on the absolute values of the MAPs which vary with the catchment size. Moreover, the RR relation depends on the catchment size and especially on the time of concentration of the catchment. The RR smoothing effect has a general tendency to increase with the area of the catchment since the streamflows result from an averaging of a larger amount of local processes over a longer period of time.

\subsubsection{Impact assessment of MAP scenarios propagation in RR models}

The 100 MAP scenarios were fed into the two calibrated RR models for the three test catchments. Particular attention is drawn to the width of the simulated streamflow uncertainty ranges in the analysis of the results. A specific criterion has been used to measure the sharpness of the streamflow simulation : the root mean square range criterion (RMSR, Eq. 17) between predefined percentiles of rainfall or streamflow scenarios distribution.

$\operatorname{RMSR}_{10-90}=\frac{1}{n} \sum_{i=1}^{n} \sqrt{\left(\mathrm{X}_{90}\left(t_{i}\right)-\mathrm{X}_{10}\left(t_{i}\right)\right)^{2}}$

where RMSR ${ }_{10-90}$ is the criterion on the variable $X$ (precipitation or streamflow) for the confidence interval $80 \%, n$ is the number of time steps, and $\mathrm{X}_{10}\left(\mathrm{t}_{i}\right)$ and $\mathrm{X}_{90}\left(\mathrm{t}_{i}\right)$ are the 10 and 90 percentiles of the variable $\mathrm{X}$ for the time $t_{i}$.

5.2 Results and discussion: impact on streamflow simulations

\subsubsection{Sharpness of RR simulations}

For each of the three catchments, the RMSR value was computed for both rainfall and streamflow series, and for various confidence intervals (Table 4). When comparing RMSR on streamflows (in $\mathrm{mm} / \mathrm{h}$ ) with RMSR on precipitation (in 
Table 4. Root mean square range (RMSR) of hourly precipitation $\mathrm{P}$ (in $\mathrm{mm} / \mathrm{h}$ ) and of streamflow Q (in $\mathrm{mm} / \mathrm{h}$ ) computed for $50 \%$, $80 \%$, $90 \%, 95 \%$ and $100 \%$ confidence intervals.

\begin{tabular}{lllrrrrrr}
\hline & & & $25-75$ & $10-90$ & $5-95$ & $2.5-97.5$ & $0-100$ & Ratio Q/P \\
\hline Rieutord & P & & 0.278 & 0.514 & 0.644 & 0.749 & 0.982 & \\
Rieutord & Q & GR4J & 0.078 & 0.148 & 0.186 & 0.217 & 0.279 & $\approx 28 \%$ \\
Rieutord & Q & TOPM & 0.076 & 0.145 & 0.182 & 0.212 & 0.275 & $\approx 28 \%$ \\
\hline Chambon & P & & 0.244 & 0.433 & 0.536 & 0.619 & 0.794 & \\
Chambon & Q & GR4J & 0.036 & 0.067 & 0.085 & 0.097 & 0.126 & $\approx 15 \%$ \\
Chambon & Q & TOPM & 0.037 & 0.068 & 0.085 & 0.098 & 0.126 & $\approx 15 \%$ \\
\hline Bas-en-Basset & P & & 0.194 & 0.360 & 0.447 & 0.515 & 0.660 & \\
Bas-en-Basset & Q & GR4J & 0.012 & 0.024 & 0.030 & 0.038 & 0.051 & $\approx 7 \%$ \\
Bas-en-Basset & Q & TOPM & 0.011 & 0.022 & 0.028 & 0.035 & 0.044 & $\approx 7 \%$ \\
\hline
\end{tabular}

Table 5. Proportion (in \%) of the observed values contained in the $90 \%$ simulated confidence interval, with and without a $20 \%$ tolerance on observed streamflow values (in [ ] in case of a tolerance of $20 \%$ but without taking into account uncertainties on MAP). $\bar{Q}$ is the mean streamflow ; $Q_{10}$ is an estimate of the 10-year flow.

\begin{tabular}{|c|c|c|c|c|c|c|c|c|c|}
\hline \multirow[b]{3}{*}{ All data } & \multicolumn{3}{|c|}{ Rieutord } & \multicolumn{3}{|c|}{ Chambon } & \multicolumn{3}{|c|}{ Bas-en-Basset } \\
\hline & \multirow{2}{*}{$\begin{array}{c}\text { Qobs } \\
22.2\end{array}$} & \multicolumn{2}{|c|}{ Qobs $\pm 20 \%$} & \multirow{2}{*}{$\begin{array}{r}\text { Qobs } \\
18.6\end{array}$} & \multicolumn{2}{|c|}{ Qobs $\pm 20 \%$} & \multirow{2}{*}{$\begin{array}{r}\text { Qobs } \\
10.9\end{array}$} & \multicolumn{2}{|c|}{ Qobs $\pm 20 \%$} \\
\hline & & 55. & {$[39.1$} & & 42.0 & {$[24.2$} & & 28.0 & [15.4] \\
\hline$Q_{\text {obs }}>10 \bar{Q}$ & 34.2 & 68.7 & [42.0] & 28.4 & 53.6 & [24.7] & 21.9 & 50.6 & [28.9] \\
\hline$Q_{\mathrm{obs}}>Q_{10}$ & 66.7 & 100.0 & {$[33.0]$} & 47.5 & 65.0 & [40.0] & 77.8 & 88.9 & {$[33.3]$} \\
\hline
\end{tabular}

$\mathrm{mm} / \mathrm{h}$ ), it appears that this ratio increases with decreasing catchment areas: RMSR on streamflow represent about $28 \%$ of RMSR on precipitation for the catchment of the Loire at Rieutord $\left(62 \mathrm{~km}^{2}\right), 15 \%$ for the Lignon at Chambon-surLignon $\left(139 \mathrm{~km}^{2}\right)$ and around $7 \%$ for the Loire River at Bas-en-Basset $\left(3234 \mathrm{~km}^{2}\right)$. There is almost no difference in sharpness between the two tested RR models.

This confirms the expected higher smoothing effect of the RR process for large catchments - at least, as simulated by the RR models. As shown in Fig. 9, the 90\% relative confidence intervals on simulated streamflows do not appear to depend anymore on the catchment: the ratio between the width of the confidence interval and the simulated streamflow values is stable and close to $50 \%$ in each case. As a first conclusion of the MAP uncertainty propagation exercise, it turns out that, for different reasons, uncertainties in MAP estimations affect streamflow simulations independent of the catchment area. This last conclusion holds for the given gauge network structure and density.

\subsubsection{Accuracy of RR simulations}

Overall, the computed $90 \%$ confidence intervals on simulated streamflow series are large. These confidence intervals have been reported on Fig. 10, along with both the measured hydrographs and the ranges of the simulated hydrographs for one of the major flood events in the record period for the upper Loire river area. The impact of the MAP uncertainties on the streamflow simulations appears to be dramatic. The upper bound of the $90 \%$ simulated confidence interval is about 1.5 times higher than the lower bound throughout the range of flows. Even if the RR models were perfect, which they are of course not, MAP estimation uncertainties set a relatively low limit to the accuracy of streamflow simulations or forecasts. Moreover, the measured hydrograph appears to be mostly contained in, or very close to, the $90 \%$ confidence interval for the two examples presented in Fig. 10 : i.e. the distance between simulated and measured hydrographs may be explained by errors in the estimation of MAPs. Similar observations are made for all the catchments and simulated streamflow series.

Table 5 gives the proportion of measured streamflows comprised in the computed $90 \%$ confidence limits for the whole test period (20-27 years) and the three catchments. A significant proportion of measured streamflows appears to be comprised in this confidence interval. This is particularly true for severe flood events (observed streamflow greater than 10 times the mean streamflow) and when a tolerance of plus or minus $20 \%$ is considered for the measured streamflows. This tolerance stands for both the streamflow measurement uncertainties and the level of efficiency of RR models expected by operational forecasters. For the smallest catchment (Rieutord), the simulated $90 \%$ confidence interval contains, depending on the discharge threshold selected, 55 to $100 \%$ of the measured streamflow values when a tolerance 

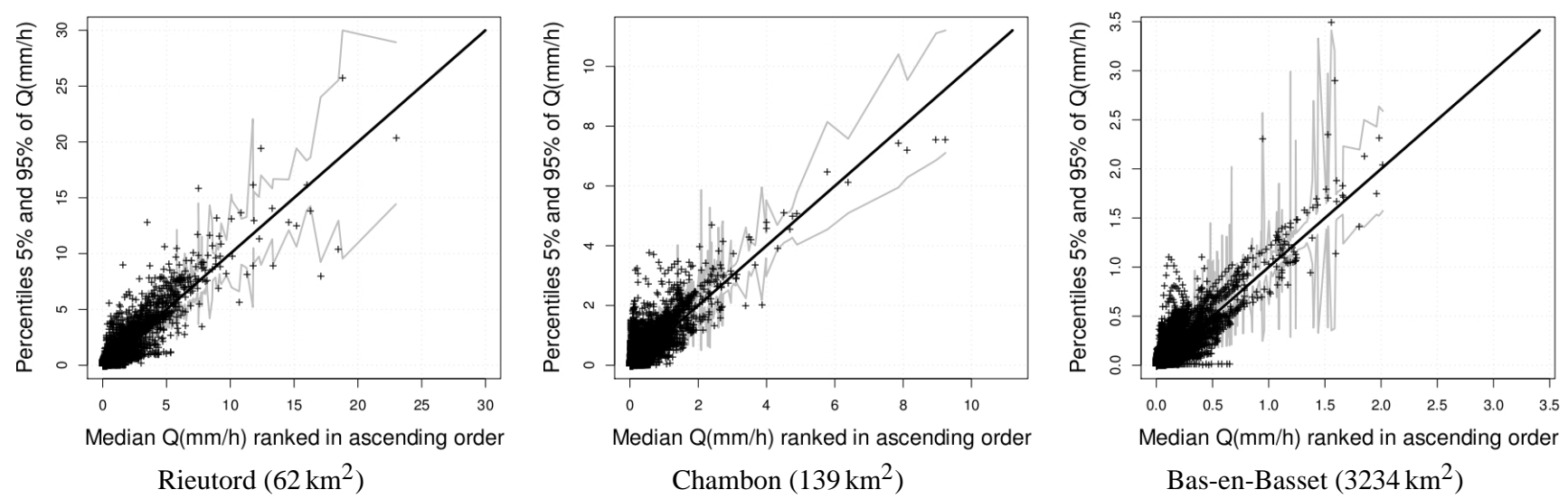

Fig. 9. Percentiles of uncertainty on streamflow $(\mathrm{mm} / \mathrm{h})$ for Rieutord (left), Chambon-sur-Lignon (center) and Bas-en-Basset (right). "+" indicate measured values versus median of simulated values.
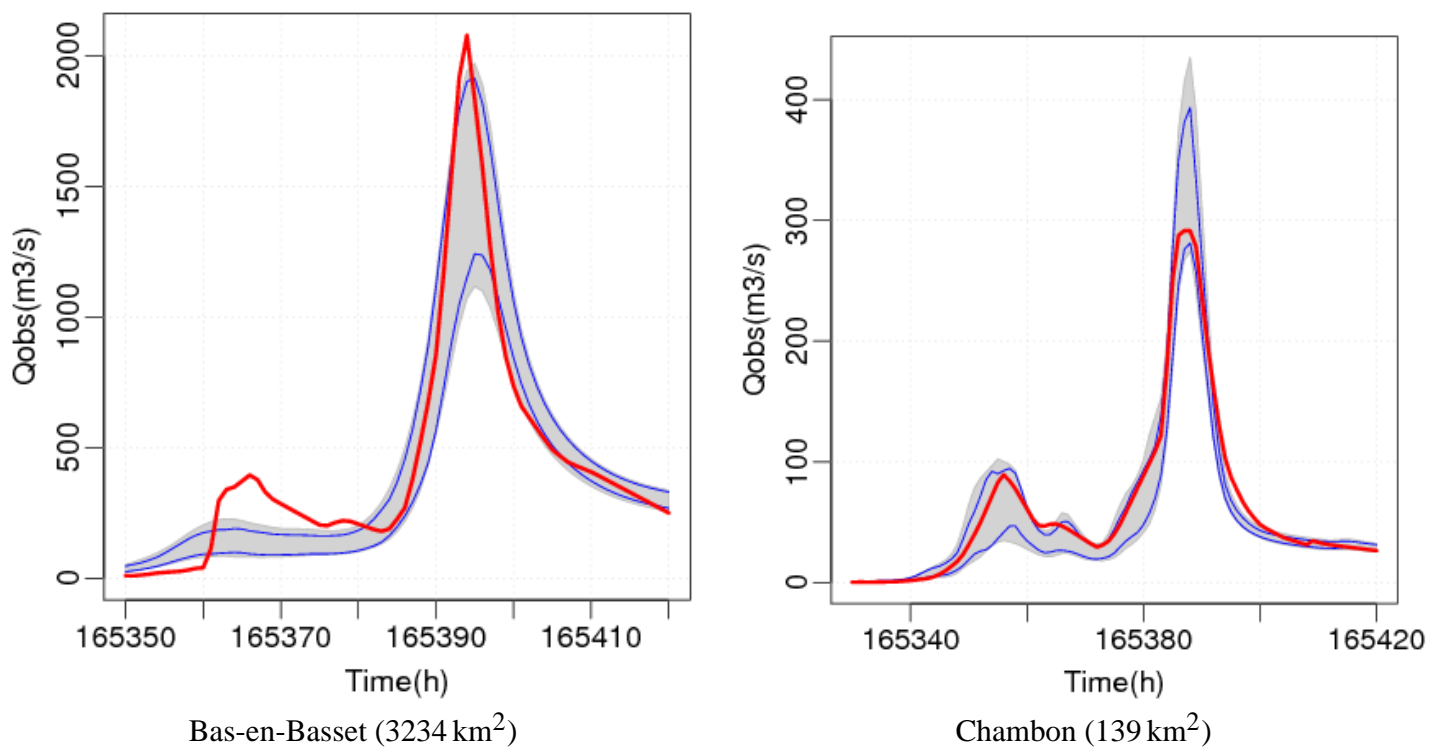

Fig. 10. Two examples of observed flood hydrographs (red lines), $90 \%$ confidence interval for the 100 simulated streamflows (grey areas) and limits of the simulated streamflow values obtained after 20 Monte Carlo runs (blue lines). Flood of 11 November 1996 at Bas-en-Basset $\left(3234 \mathrm{~km}^{2}\right.$, left) and Chambon-sur-Lignon $\left(139 \mathrm{~km}^{2}\right.$, right).

factor of $20 \%$ is considered (Table 5). In other words, rainfall estimation uncertainties may explain a large part of the differences between measured and simulated streamflows. Rainfall estimation uncertainties appear in this case as a major factor limiting the accuracy of streamflow simulations. Conversely, according to the existing uncertainties on estimated MAPs and their impact on RR simulations, RR simulation accuracy will hardly be improved without a significant reduction of the MAP estimation errors. This pleads for an improvement of the rainfall measurement networks and techniques.
For the largest catchments of the Lignon at Chambon and of the Loire river at Bas-en-Basset, theoretical uncertainties on MAP are nevertheless far from explaining all of the RR modelling errors, especially when low discharge values are considered. The Lignon catchment located on a relief is frequently affected by heavy rainfalls that are not well captured by the existing surrounding raingauge network. The proposed error model tends to under-estimate the error standard deviation in this area according to the cross-validation results obtained for the Fay raingauge located on the Lignon catchment (see Table 3). In the case of the Loire river at Basen-Basset, other error sources seem to affect significantly the 
RR simulations. A detailed analysis of the simulated and observed hydrographs reveals delays and apparent fluctuations of both the runoff rates and the times-to-peak between events. These can undoubtedly be attributed, to a great extent, to the spatial repartition of the rainfall. Higher runoff rates are generally observed during convective events when the rainfall is concentrated on a limited part of the catchment if compared to stratiform events with a more homogeneous rainfall repartition. Likewise, the time-to-peak depends on the location of the rain cells on the catchment and their distance to the outlet for convective rainfall events. The tested lumped modelling approach becomes limited on catchments of this size. For larger catchment areas, according to the results presented herein, the use of distributed or semi-distributed hydrological models might bring some improvements to the RR simulations. Nevertheless, this possible gain should be put into perspective by considering the number of calibrated parameters: problems such as over-parameterisation might emerge.

As a conclusion to this MAP uncertainty propagation exercise, a significant part of the streamflow simulation error may be attributed to MAP estimation errors, except on large catchments (typically areas over $500 \mathrm{~km}^{2}$ ) where the shape of the hydrograph can be influenced by the spatio-temporal pattern of the rainfall event, and where a spatialised modelling approach might bring improvement if compared to the tested lumped models. Even if the RR models were perfect, MAP estimation uncertainties are clearly a major constraint on both accuracy and sharpness of stream flow simulations or forecasts.

\section{Summary and conclusions}

The objective of this study was twofold: to propose a reliable estimate of MAP uncertainties when MAPs are obtained through the interpolation of raingauge measurements and to investigate the possible impact of MAP estimation errors on RR simulations.

When compared to previous published results on the same issue, the main originality of this study lies in the development and partial validation of a reliable error model (consistent with the data) to represent uncertainties in MAP. Whereas most of the previous studies use either completely empirical error estimations or a priori error models, we propose a time-dependent spatial error model based on geostatistics and which has been validated to the greatest possible extent.

Monte Carlo simulations based on this error model reveal that uncertainties on MAP estimations induce large uncertainties in RR simulations. For different reasons, all the tested catchments are equally affected by this phenomenon: the relative size of the computed confidence interval is independent on the catchment area. The higher relative error values on MAPs appear to be compensated by a higher smoothing effect of the RR transformation when larger catchment areas are considered.
Comparison with measured streamflows shows that a significant part of the lumped RR simulation errors may be explained by the uncertainties in MAP estimations. This is particularly true for the smallest catchments studied, whereas on the larger catchment the shape of the hydrograph can be influenced by the spatio-temporal pattern of the rainfall event and distributed RR models might bring an improvement if compared to the tested lumped models. This implies that for a certain range of catchment areas (up a few hundred square kilometers), MAP estimation uncertainties drastically restrict the possible accuracy of streamflow simulations and set a limit to both future developments and improvements of RR models. Even in an optimal situation - good quality and long datasets, intensive effort in RR model selection and calibration - RR simulation errors can be reduced with difficulty, without a significant improvement of the rainfall measurement networks and techniques.

From a practical point of view, operational forecasting services should be aware of these limits to the efficient use of RR models and if possible evaluate the RR simulation uncertainties in real time to be able to deliver confidence intervals along with their traditional deterministic forecasts. Ensemble or Monte Carlo forecasts are now used routinely in meteorological forecasting; there is no reason why they should be disregarded by hydrologists. The error scenario simulation model developed here could help to build such ensemble forecasts in the case where MAP amounts are estimated through a rain gauge network. The same type of model is still to be developed for the case where quantitative radar estimations are used.

Acknowledgements. The work described in this publication was supported by the European Community's Sixth Framework Programme through the grant to the budget of the Integrated Project FLOODsite, Contract GOCE-CT-2004-505420. It has also benefited from the financial support of the Direction Régionale de l'Environnement Centre and of the Établissement Public Loire. Part of the data was provided by MeteoFrance and Électricité de France (EDF).

Edited by: A. Montanari

\section{References}

Anctil, F., Lauzon, N., Andreassian, V., Oudin, L., and Perrin, C.: Improvement of rainfall-runoff forecasts through mean areal rainfall optimization, J. Hydrol., 328, 717-725, 2006.

Andrieu, H., French, M. N., Krajewski, W. F., and Georgakakos, K. P.: Stochastic-dynamical rainfall simulation based on weather radar volume scan data, Adv. Water Resour., 26, 581-593, 2003.

Balme, M., Vischel, T., Lebel, T., Peugeot, C., and Galle, S.: Assessing the water balance in the Sahel: Impact of small scale rainfall variability on runoff: Part 1: Rainfall variability analysis, J. Hydrol., 331, 336-348, 2006.

Bardossy, A. and Das, T.: Influence of rainfall observation network on model calibration and application, Hydrol. Earth Syst. Sci., 12, 77-89, 2008, http://www.hydrol-earth-syst-sci.net/12/77/2008/. 
Beven, K. and Kirby, M.: A physically-based, variable contributing area model of basin hydrology, Hydrol. Sci. B., 23, 419-438, 1979.

Borga, M.: Accuracy of radar rainfall estimates for streamflow simulation, J. Hydrol., 267, 26-39, 2002.

Borga, M., Degli Esposti, S., and Norbiato, D.: Influence of errors in radar rainfall estimates on hydrological modeling prediction uncertainty, Water Resour. Res., 42, W08 409, doi:10.1029/2005WR00459, 2006.

Chahinian, N., Andreassian, V., Duan, Q., Fortin, V., Gupta, H., Hogue, T., Mathevet, T., Montanari, A., Moretti, G., Moussa, R., Perrin, C., Schaake, J., Wagener, T., and Xie, Z.: Comparison of the MOPEX 2004 results, in: Large Sample Basin Experiments for Hydrological Model parameterization: Results of the Model Parameter Experiment - MOPEX, IAHS Red Books 307, Wallingford, 313-338, 2006.

Carpenter, T. M. and Georgakakos, K. P.: Impacts of parametric and radar rainfall uncertainty on the ensemble streamflow simulations of a distributed hydrologic model, J. Hydrol., 298, 202221, 2004.

Carpenter, T. M., Georgakakos, K. P., and Sperfslagea, J. A.: On the parametric and NEXRAD-radar sensitivities of a distributed hydrologic model suitable for operational use, J. Hydrol., 253, 169-193, 2001.

Chapon, B., Delrieu, G., Gosset, M., and Boudevillain, B.: Variability of rain drop size distribution and its effect on the Z-R relationship: A case study for intense Mediterranean rainfall, Atmos. Res., 87, 52-65, 2008.

Chen, Y.-C., Wei, C., and Yeh, H.-C.: Rainfall network design using kriging and entropy, Hydrol. Process., 22, 330-346, 2008.

Cole, S. J. and Moore, R. J.: Hydrological modelling using raingauge- and radar-based estimators of areal rainfall, J. Hydrol., 358(3), 159-181, 2008.

Creutin, J. and Obled, Ch.: Objectives analyses and mapping techniques for rainfall fields : an objective comparison, Water Resour. Res., 18, 413-431, 1982.

Datin, R.: Outils opérationnels pour la prévision des crues rapides: traitements des incertitudes et intégration des prévisions météorologiques. Développements de TOPMODEL pour la prise en compte de la variabilité spatiale de la pluie. Application au bassin versant de l'Ardèche., Ph.D. thesis, Institut National Polytechnique de Grenoble, Grenoble, 369 pp., 1998.

Delrieu, G.: The Cevennes-Vivarais Mediterranean Hydrometeorological observatory, Houille Blanche, 6, 83-88, 2003.

Delrieu, G., Ducrocq, V., Gaume, E., Nicol, J., Payrastre, O., Yates, E., Kirstetter, P. E., Andrieu, H., Ayral, P. A., Bouvier, C., Creutin, J. D., Livet, M., Anquetin, S., Lang, M., Neppel, L., Obled, C., Parent-du Chatelet, J., Saulnier, G. M., Walpersdorf, A., and Wobrock, W.: The catastrophic flash-flood event of 8-9 September 2002 in the Gard region, France: A first case study for the Cevennes-Vivarais Mediterranean Hydrometeorological Observatory, J. Hydrometeorol., 6, 34-52, 2005.

Dulal, K., Takeuchi, K., and Ishidaira, H.: A framework for the Analysis of Uncertainty in the Measurement of Precipitation Data: a case study for Nepal., in: Agricultural Engineering International: the CIGR E-journal, Manuscript LW 06 100, Vol VIII., 2006.
Edijatno, Nascimento, N., Yang, X., Makhlouf, Z., and Michel, C.: GR3J: a daily watershed model with three free parameters, Hydrolog. Sci. J., 44(2), 263-277, 1999.

Gourley, J. J. and Vieux, B. E.: A method for identifying sources of model uncertainty in rainfall-runoff simulations, J. Hydrol., 327(1-2), 68-80, 2006.

Haberlandt, U.: Geostatistical interpolation of hourly precipitation from rain gauges and radar for a large-scale extreme rainfall event, J. Hydrol., 332, 144-157, 2007.

Jakeman, A. and Hornberger, G.: How much complexity is warranted in a rainfall-runoff model?, Water Resour. Res., 29(8), 2637-2649, 1993.

Johansson, B.: Areal precipitation and temperature in the Swedish mountain, An evaluation from a hydrological perspective, Nord. Hydrol., 31, 207-228, 2000.

Kieffer-Weisse, A. and Bois, P.: A comparison of methods for mapping statistical characteristics of heavy rainfall in the French Alps: the use of daily information, Hydrolog. Sci. J., 47(5), 739752, 2002.

Klemeš, V.: Operationnal testing of hydrological simulation models, Hydrolog. Sci. J., 31(1), 13-24, 1986.

Krajewski, W. F. and Smith, J.: Radar hydrology : rainfall estimation., Adv. Water Resour., 25(8-12), 1387-1394, 2002.

Lebel, T., Bastin, G., Obled, Ch., and Creutin, J.: On the accuracy of areal rainfall estimation: a case study, Water Resour. Res., 23, 2123-2134, 1987.

Mathevet, T.: Quels modèles pluie-debit globaux au pas de temps horaire? Développements empiriques et intercomparaison de modèles sur un large échantillon de bassins versants, Ph.D. thesis, ENGREF, 463 pp., 2005.

Melching, C.: Computer Models of Watershed Hydrology, Chap. 3, Reliability estimation, 69-118, 1995.

Michaud, J., and Sorooshian, S.: Comparison of simple versus complex distributed runoff models on a midsized semiarid watershed, Water Resour. Res., 30, 593-605, 1994.

Moulin, L.: Prévision des crues rapides avec des modèles hydrologiques globaux. Application aux bassins opérationnels de la Loire supérieure: évaluation des modélisations, prise en compte des incertitudes sur les précipitations moyennes spatiales et utilisation de prévisions météotorologiques, Ph.D. thesis, ENGREF, 643 pp., 2007.

Nandakumar, N. and Mein, R. G.: Uncertainty in rainfall-runoff model simulations and the implications for predicting the hydrologic effects of land-use change, J. Hydrol., 192, 211-232, 1997.

Nash, J. and Sutcliffe, J.: River flow forecasting through conceptual models. Part I - A discussion of principles., J. Hydrol., 10(3), 282-290, 1970.

Oudin, L., Perrin, C., Mathevet, T., Andreassian, V., and Michel, C.: Impact of biased and randomly corrupted inputs on the efficiency and the parameters of watershed models, J. Hydrol., 320, 62-83, 2006.

Paturel, J. E., Servat, E., and Vassiliadis, A.: Sensitivity of conceptual rainfall-runoff algorithms to errors in input data - case of the GR2M model, J. Hydrol., 168, 111-125, 1995.

Perrin, C., Michel, C., and Andreassian, V.: Does a large number of parameters enhance model performance? Comparative assessment of common catchment model structures on 429 catchments, J. Hydrol., 242, 275-301, 2001. 
Perrin, C., Michel, C., and Andreassian, V.: Improvement of a parsimonious model for streamflow simulation, J. Hydrol., 279, 275289, 2003.

Refsgaard, J. C., van der Sluijs, J. P., Brown, J., and van der Keur, P.: A framework for dealing with uncertainty due to model structure error, Adv. Water Resour., 29, 1586-1597, 2006.

Retnam, M. T. P. and Williams, B. J.: Input errors in rainfall-runoff modelling, Math. Comput. Simulat., 30, 119-131, 1988.

Rode, M. and Suhr, U.: Uncertainties in selected river water quality data, Hydrol. Earth Syst. Sci., 11, 863-874, 2007, http://www.hydrol-earth-syst-sci.net/11/863/2007/.

Segond, M. L., Wheater, H. S., and Onof, C.: The significance of spatial rainfall representation for flood runoff estimation: A numerical evaluation based on the Lee catchment, UK, J. Hydrol., 347, 116-131, 2007.

Storm, B., Jensen, K. H., and Refsgaard, J. C.: Estimation of catchment rainfall uncertainty and its influence on runoff prediction, Nord. Hydrol., 19, 77-88, 1989.
Sun, X., Mein, R. G., Keenan, T. D., and Elliott, J. F.: Flood estimation using radar and raingauge data, J. Hydrol., 239, 4-18, 2000.

Villarini, G., Mandapaka, P., Krajewski, W., and Moore, R.: Rainfall and sampling uncertainties: A rain gauge perspective., J. Geophys. Res., 113, D11102, doi:10.1029/2007JD009214, 2008.

Vischel, T. and Lebel, T.: Assessing the water balance in the Sahel: Impact of small scale rainfall variability on runoff. Part 2: Idealized modeling of runoff sensitivity, J. Hydrol., 333, 340-355, 2007.

Xu, C. Y. and Vandewiele, G. L.: Sensitivity of monthly rainfallrunoff models to input errors and data length, Hydrolog. Sci. J., 39, 157-176, 1994. 